\title{
TERT promoter mutations in penile squamous cell carcinoma: high frequency in non-HPV-related type and association with favorable clinicopathologic features
}

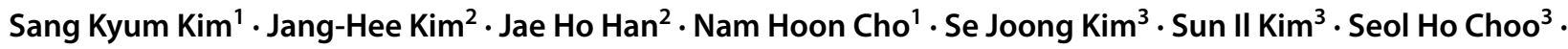 \\ Ji Su Kim ${ }^{4} \cdot$ Bumhee Park ${ }^{4,5}$ • Ji Eun Kwon²
}

Received: 10 August 2020 / Accepted: 9 January 2021 / Published online: 26 February 2021

(c) The Author(s) 2021

\begin{abstract}
Purpose Penile carcinoma is a rare malignant neoplasm with a largely unknown molecular pathogenesis. Telomerase reverse transcriptase promoter (TERT-p) mutations have been detected in several types of human malignancies. The aim of this study was to investigate the presence of TERT-p mutations in penile squamous cell carcinomas (SCCs) and their associations with clinicopathologic features.

Methods In this retrospective study, Sanger sequencing was performed to detect TERT-p mutations in formalin-fixed paraffin-embedded tissue samples from 37 patients with penile SCC, 16 patients with cutaneous SCC, and 4 patients with nonneoplastic penile/skin tissue. The expression of p16 ${ }^{\mathrm{INK} 4 \mathrm{a}}$ and Ki-67 was investigated via immunohistochemistry. Associations of TERT-p mutation with clinicopathological factors, immunohistochemical results, and clinical outcome were statistically analyzed.

Results Recurrent TERT-p mutations were identified in 18 out of 37 (48.6\%) penile SCCs, including all 3 carcinoma in situ cases. TERT-p mutations were significantly more frequent in non-human papilloma virus (HPV)-related penile SCC types than in non-HPV-related penile SCC based on both histologic classification and p16 ${ }^{\mathrm{INK} 4 \mathrm{a}}$ immunoreactivity. Furthermore, TERT-p mutation was associated with a low histologic grade, low mitotic count, absence of necrosis, low Ki-67/MIB-1 labeling index, and absence of lymph node or distant metastasis.

Conclusion Our study shows TERT-p mutations are the most frequent somatic mutations in penile SCC. In addition, TERT-p mutations are far more frequent in non-HPV-related penile SCC than in HPV-related penile SCC, indicating TERT-p mutations may have a role in tumorigenesis distinct from HPV-related penile SCC.
\end{abstract}

Keywords TERT promoter $\cdot$ Penile cancer $\cdot$ Human papillomavirus $\cdot$ Telomerase

\author{
Ji Eun Kwon \\ kjefullup@aumc.ac.kr \\ Sang Kyum Kim \\ NICEKYUMI@yuhs.ac \\ Jang-Hee Kim \\ drjhk@aumc.ac.kr \\ Jae Ho Han \\ hanpathol@aumc.ac.kr \\ Nam Hoon Cho \\ CHO1988@yuhs.ac \\ Se Joong Kim \\ sejoong@ajou.ac.kr \\ Sun Il Kim \\ sikimuro@aumc.ac.kr \\ Seol Ho Choo \\ shchoo@aumc.ac.kr
}

Ji Su Kim

k.jisu5107@aumc.ac.kr

Bumhee Park

bhpark@aumc.ac.kr

1 Department of Pathology, Severance Hospital, Yonsei University College of Medicine, Seoul, Republic of Korea

2 Department of Pathology, Ajou University School of Medicine, 164, Worldcup-ro, Yeongtong-gu, Suwon 16499, Republic of Korea

3 Department of Urology, Ajou University School of Medicine, Suwon, Republic of Korea

4 Office of Biostatistics, Medical Research Collaborating Center, Ajou Research Institute for Innovation, Ajou University Medical Center, Suwon, Republic of Korea

5 Department of Biomedical Informatics, Ajou University School of Medicine, Suwon, Republic of Korea 


\section{Introduction}

Penile carcinoma is a rare malignant neoplasm with an incidence of 1-4 per 100,000 in developing countries and is even rarer in developed countries (Rubin et al. 2001). Squamous cell carcinoma (SCC) and its histologic variants account for approximately $95 \%$ of all cases of penile carcinoma (Suarez-Bonnet et al. 2018). Pathologically, penile carcinomas are classified into two distinct groups based on clinicopathologic characteristics and an association with HPV infection: human papilloma virus (HPV)-related and non-HPV-related type (Mannweiler et al. 2013). HPV high-risk (HPV-HR) DNA is detected in $20-80 \%$ of penile carcinomas, and plays a role in the carcinogenesis of HPV-related penile SCC (Spiess et al. 2016). The detection rates of HPV DNA vary depending on histologic subtypes (Cubilla et al. 2016). Unlike SCC of the uterine cervix, which is caused by HPV in $100 \%$ of cases, only about $1 / 3-1 / 2$ of penile carcinomas are caused by transforming HPV infection. The non-HPV-related penile SCC develops in the background of chronic inflammatory skin diseases such as lichen sclerosus and lichen planus. HPV-HR16 is known to be the most prevalent HPV DNA type in HPV-related penile SCC (Rubin et al. 2001). The viral oncogenes of HPV, E6 and E7, bind to the tumor-suppressor proteins p53 and RB, respectively, leading to their inactivation, thereby affecting the cell cycle and apoptosis and resulting in unchecked replication of DNA and continued cell proliferation (Spiess et al. 2016). Consequently, $\mathrm{p} 16^{\mathrm{INK} 4 \mathrm{a}}$ protein, a cyclin-dependent kinase inhibitor, accumulates, which can be identified by $\mathrm{p} 16^{\mathrm{INK} 4 \mathrm{a}}$ immunohistochemistry (Aumayr et al. 2013).

Along with technological advances in the past decade, genetic alterations in cancers have been extensively disclosed, ushering in a new era of precision medicine in cancer treatment (Baudino 2015). However, this has not been the case for penile cancer, as the underlying molecular pathogenesis is yet to be elucidated, which is most likely due to the rarity of penile SCC. Accordingly, no standardized treatment or personalized medicine has been established for penile cancer (Kim et al. 2018).

The telomerase reverse transcriptase (TERT) gene encodes the catalytic subunit of telomerase that is responsible for telomere lengthening at chromosomal ends (Vinagre et al. 2014). Normal somatic cells and benign tumor cells lack telomerase activity, whereas telomerase is active in germ cells and stem cells of self-renewing tissues (Gunes and Rudolph 2013), and is found to be reactivated in up to $90 \%$ of cancer cells (Kyo et al. 2008). Reactivation of telomerase maintains the telomere length and enables cancer cells to evade senescence resulting from telomere shortening. Novel recurrent somatic mutations in the core promoter region of TERT were recently identified in $\sim 70 \%$ of melanoma samples examined by nextgeneration sequencing, which have now become the most frequently detected mutation in malignant melanoma (Horn et al. 2013; Huang et al. 2013). Subsequently, these mutations were also detected at high frequencies in several other human malignancies, including thyroid carcinoma, glioma, bladder carcinoma, hepatocellular carcinoma, and various types of non-melanoma skin cancers such as SCC and basal cell carcinoma (Arita et al. 2013; Allory et al. 2014; Chen et al. 2014a, b; Griewank et al. 2013; Liu et al. 2013a, b; Populo et al. 2014; Scott et al. 2014). By contrast, TERT promoter (TERT-p) mutations have not been detected or have been detected at very low frequency in malignant tumors of other organs (Cheng et al. 2015; Huang et al. 2013; van Nistelrooij et al. 2014). In addition, the clinical relevance of these mutations has been highlighted based on significant associations with poor patient outcome or adverse clinicopathologic parameters in various cancers (Chen et al. 2014a, b; Kinde et al. 2013; Griewank et al. 2014; Melo et al. 2014; Qu et al. 2014; Simon et al. 2015). TERT-p mutations create de novo binding sites for E-twenty-six (ETS) transcription factors (CCG GAA) within the TERT-p region. An in vitro luciferase assay also showed that these mutations resulted in a twoto fourfold increase of TERT promoter activity (Huang et al. 2013). Despite continuing research on TERT-p mutation in human cancers, including a recent study describing the varying frequency of TERT-p mutation in SCCs arising from various organs (Cheng et al. 2015), TERT-p mutation in penile SCC has not been investigated to date.

Therefore, the aim of the present study was to investigate the presence of TERT-p mutations in penile SCC, and their associations with clinicopathologic parameters, along with p16 ${ }^{\mathrm{INK} 4 \mathrm{a}}$ and Ki-67/MIB-1 expression.

\section{Methods}

\section{Case selection}

The study was approved by the Institutional Review Boards (IRB) of Ajou University School of Medicine and Yonsei University Health System, and performed in accordance with the Declaration of Helsinki. Informed consent was waived by the IRB for this retrospective study. Thirty-seven formalin-fixed, paraffin-embedded penile carcinoma tissues surgically resected from patients in the time period between 2000 and 2017 were retrieved from the archives of the Department of Pathology of Ajou University School of Medicine (23 cases) and the Department of Pathology of Yonsei University College of Medicine (14 cases) based on the availability of tissue blocks or slides for histopathologic 
analyses and DNA extraction. Among the 37 cases, there were three cases of carcinoma in situ (CIS) included. In addition, 16 cases of cutaneous SCC and 4 samples of nontumor skin or penile tissue were used as positive and negative controls, respectively, for TERT-p sequencing.

\section{DNA extraction and direct sequencing}

The tumors were manually dissected from $10-\mu \mathrm{m}$ sections of formalin-fixed, paraffin-embedded tissues. Genomic DNA was extracted using the QIAamp kit (Qiagen, Hilden, Germany) according to the manufacturer's instructions. Polymerase chain reaction (PCR) amplification of the TERT promoter region was performed using the primer pair $\mathrm{hTERT}$ _F (CAC CCG TCC TGC CCC TTC ACC TT)/hTERT_R (CAG CGC TGC CTG AAA CTC), generating an expected 304bp product. The cycling conditions for PCR amplification were $95^{\circ} \mathrm{C}$ for $2 \mathrm{~min}$ for denaturation, and 35 cycles of $95^{\circ} \mathrm{C}$ denaturation for $30 \mathrm{~s}, 60{ }^{\circ} \mathrm{C}$ annealing for $30 \mathrm{~s}$, and $72{ }^{\circ} \mathrm{C}$ elongation for $40 \mathrm{~s}$. PCR products were confirmed by gel electrophoresis. Direct sequencing of both strands was performed using a BigDye terminator v3.1 cycle sequencing kit (Applied Biosystems, Foster City, CA, USA) on an ABI 3500XL genetic analysis system (Applied Biosystems).

\section{Clinicopathologic features}

All hematoxylin and eosin-stained slides from the tumors were reviewed independently by two pathologists who were blinded to other clinical and genetic information. Clinical data were collected from the medical records. The factors investigated were as follows: histologic subtype, grade, presence and type of penile intraepithelial neoplasia (PeIN), lymphovascular invasion, perineural invasion, ulceration, tumor thickness, necrosis, mitotic count, koilocytosis, acantholysis, tumor-infiltrating lymphocytes, intraepithelial neutrophilic microabscess, peripheral tumor budding (Shimizu et al. 2018), tumor size, gross type, patient age, stage, lymph node or distant metastasis, and patient survival (Online Resource 1-3). Histologic subtype was classified into HPV-related type and non-HPV-related type according to the World Health Organization guidelines 2016 (Cubilla et al. 2016). A mixed HPV-related and non-HPV-related type was considered a HPV-related type for statistical analyses. The mitotic count was calculated from 10 contiguous highpower fields located in the most mitotically active tumor region.

\section{Immunohistochemistry for $\mathrm{p} 16^{\mathrm{INK} 4 \mathrm{a}}$ and Ki-67}

Immunohistochemical staining for $\mathrm{p} 16^{\mathrm{INK} 4 \mathrm{a}}$ and Ki-67 was performed on one representative block of all samples on a BenchMark XT autostainer (Ventana Medical Systems,
Tucson, AZ, USA) according to the manufacturer's protocol using a ready-to-use mouse monoclonal $\mathrm{p} 16^{\mathrm{INK} 4 \mathrm{a}}$ antibody (CINtec p16 Histology, clone E6H4, Sedona, USA) and an anti-human mouse monoclonal Ki-67 antibody (1:100, clone MIB-1, DAKO, Copenhagen, Denmark). Only strong continuous staining of $\mathrm{p} 16^{\mathrm{INK} 4 \mathrm{a}}$ was considered positive. Weak or spotty, patchy, and discontinuous staining was considered negative (Katzenellenbogen 2017a, b). For the Ki-67 stain, any distinct nuclear staining was recorded as positive. The Ki-67 (MIB-1) labeling index, defined as the percentage of positively stained tumor cells, was measured by computerassisted manual counting of at least 1000 tumor nuclei from the area of maximal labeling using Image-Pro Plus 4.5 software.

\section{Statistical analyses}

Statistical analyses were performed using SPSS v22.0 (SPSS Inc., Chicago, IL, USA). The relation between TERT-p mutation and clinicopathologic parameters was evaluated using the $\chi^{2}$ test or Fisher's exact test and the Mann-Whitney $U$ test for categorical and continuous variables, respectively. Kaplan-Meier survival analysis and the log-rank test were used to analyze the prognostic effect of TERT-p mutation in terms of both disease-free survival (DFS) and overall survival (OS). Univariate and multivariate regression analyses were performed using the Cox proportional hazards model. A $P$ value $<0.05$ was considered significant. We conducted a power analysis for determining an appropriate sample size in Cox proportional hazard regression analysis using PASS v14.0.14.

\section{Results}

\section{Study cohort}

The age at diagnosis for the included patients was $65.97 \pm 12.18$ years (range $40-87$ years). Of the 37 penile SCCs, 17 were HPV-related type and 20 were non-HPVrelated type. Follow-up data were available for all 37 cases, and the follow-up period ranged from 4 months to 13.8 years (median 80.47 months). Seven patients died of the disease (Table 1).

\section{TERT-p mutations are frequent in penile SCC}

Of the 37 penile SCCs, including the 3 cases of CIS, 18 cases (48.6\%) harbored TERT-p mutations, including c. $-146 \mathrm{C}>\mathrm{T}$, c. $-124 \mathrm{C}>\mathrm{T}$, and c.-124 C $>$ A. All three CIS tumors harbored the c. $-146 \mathrm{C}>\mathrm{T}$ mutation. Ten (62.5\%) of the 16 skin SCCs had TERT-p mutations, which were located at positions c. $-146 \mathrm{C}>\mathrm{T}$, c. $-124 \mathrm{C}>\mathrm{T}$, and c. $-139+-138 \mathrm{CC}>\mathrm{TT}$ 
Table 1 Summary of patient characteristics

\begin{tabular}{|c|c|}
\hline Characteristics & $N=37$ \\
\hline \multicolumn{2}{|l|}{ Age at diagnosis (years) } \\
\hline Mean \pm SD & $65.97 \pm 12.18$ \\
\hline Range & $40-87$ \\
\hline \multicolumn{2}{|l|}{ Tumor size $(\mathrm{cm})$} \\
\hline Mean \pm SD & $3.59 \pm 2.43$ \\
\hline Range & $1-14$ \\
\hline \multicolumn{2}{|l|}{ Histologic type (no. of patient) } \\
\hline HPV-related & 17 \\
\hline Non-HPV-related & 20 \\
\hline \multicolumn{2}{|l|}{ AJCC stage (no. of patient) } \\
\hline I & 8 \\
\hline II & 18 \\
\hline III & 5 \\
\hline IV & 6 \\
\hline \multicolumn{2}{|l|}{ Grade (no. of patient) } \\
\hline 1 (well differentiated) & 10 \\
\hline 2 (moderately differentiated) & 9 \\
\hline 3 (poorly differentiated) & 18 \\
\hline \multicolumn{2}{|l|}{ Gross type (no. of patient) } \\
\hline Superficial spreading ${ }^{\mathrm{a}}$ & 8 \\
\hline Verrucous & 13 \\
\hline Vertical & 16 \\
\hline \multicolumn{2}{|l|}{ Surgery (no. of patient) } \\
\hline Total penectomy & 6 \\
\hline Partial penectomy & 28 \\
\hline Excision & 3 \\
\hline Lymph node biopsy or dissection & 14 \\
\hline \multicolumn{2}{|l|}{ Adjuvant therapy } \\
\hline Chemotherapy, only & 3 \\
\hline Radiotherapy, only & 2 \\
\hline Chemoradiotherapy & 4 \\
\hline \multicolumn{2}{|l|}{ Follow-up duration (month) } \\
\hline Median & 80.47 \\
\hline Range & $4-166$ \\
\hline \multicolumn{2}{|l|}{ Metastasis (no. of patient) } \\
\hline Lymph node & 10 \\
\hline Distant metastasis & 7 \\
\hline Bone & 3 \\
\hline Lung & 4 \\
\hline \multicolumn{2}{|l|}{ Clinical outcome (no. of patient) } \\
\hline Alive & 22 \\
\hline Died of disease & 7 \\
\hline Died of other cause & 5 \\
\hline
\end{tabular}

$S D$ standard deviation, AJCC the American Joint Committee on Cancer

${ }^{\mathrm{a}}$ The three cases of carcinoma in situ were included
(Online Resource 4). The four negative control samples (non-neoplastic penile or skin tissue) all showed the wildtype $T E R T$-p sequence (Table 2).

\section{Correlation of TERT-p mutation status with clinicopathologic parameters}

To explore potential associations between TERT-p mutation status and clinicopathologic parameters, statistical analyses were performed on the 24 invasive SCCs, excluding the three CIS cases. TERT-p mutations were more frequent in non-HPV-related type than in HPV-related type penile SCCs $(13 / 20,86.7 \%$ vs $2 / 14,13.3 \%$; $p=0.005)$. In line with this finding, TERT-p mutations correlated with the presence of differentiated PeIN, which is a precursor lesion associated with non-HPV-related type penile SCC $(p=0.005)$. $T E R T$-p mutations were also more frequent in tumors with a lower histologic grade $(p=0.036)$, lower mitotic activity $(p=0.001)$, absence of necrosis $(p=0.045)$, larger tumor size $(p=0.045)$, and absence of lymph node or distant metastasis $(p=0.020)$ (Table 3$)$.

\section{Correlation of TERT mutation status with p16 ${ }^{\mathrm{INK} 4 a}$ and MIB-1 immunohistochemistry}

$\mathrm{p} 16^{\mathrm{INK} 4 \mathrm{a}}$ positivity was more frequent in TERT-p wild-type tumors $(12 / 19,63.2 \%)$ than in TERT-p mutant tumors $(1 / 15$, $6.7 \% ; p=0.001)$, which is consistent with the above result that $T E R T$-p mutations were more frequent in non-HPVrelated type than in HPV-related type penile SCC. In addition, the MIB-1 labeling index was significantly higher in $T E R T$-p wild-type tumors $(45.26 \pm 19.38)$ than in TERT-p mutant tumors $(31.80 \pm 11.89 ; p=0.014$; Fig. 1$)$.

\section{Effects of TERT-p mutations on prognosis of patients with penile SCC}

We performed a power analysis to estimate the adequacy of sample size for Cox regression analysis in our study. A sample size of 34 subjects (wild group $=19$, mutant group $=15$ ) was determined to be optimal with $94.90 \%$ statistical power, a significance level of $p<0.05$, and hazard ratio $=0.101(=1 / 9.86)$. As shown in Fig. 2, patients with TERT-p-mutated tumors showed significantly longer DFS compared with that of patients with TERT-p wild-type tumors $(p=0.009)$. However, there was no difference in OS between patients with TERT-p-mutated and wild-type tumors (data not shown). A significant positive correlation between TERT-p mutation and DFS was confirmed by the univariate Cox regression analysis (hazard ratio $0.10,95 \%$ CI 0.01-0.82). However, in the multivariate Cox regression analysis, TERT-p mutation status was not an independent factor affecting DFS (Table 4). 
Table 2 TERT promoter mutations identified in penile squamous cell carcinoma and control tissues

\begin{tabular}{|c|c|c|c|c|c|c|c|}
\hline \multirow[t]{2}{*}{ Tissue } & \multirow{2}{*}{$\begin{array}{l}N \\
(\%)\end{array}$} & \multicolumn{5}{|c|}{$T E R T$-p mutant } & \multirow[t]{2}{*}{$T E R T$-p wild } \\
\hline & & Overall & c. $-146 \mathrm{C}>\mathrm{T}$ & c. $-124 \mathrm{C}>\mathrm{T}$ & c. $-124 \mathrm{C}>\mathrm{A}$ & c. $-139 \_-138 \mathrm{CC}>\mathrm{TT}$ & \\
\hline Penile SCC invasive & $34(100 \%)$ & $15(44.1 \%)$ & $11(32.3 \%)$ & $3(8.8 \%)$ & $1(2.9 \%)$ & 0 & $19(55.8 \%)$ \\
\hline Penile SCC in situ & $3(100 \%)$ & $3(100 \%)$ & $3(100 \%)$ & 0 & 0 & 0 & 0 \\
\hline Penile SCC in situ and invasive & $37(100 \%)$ & $18(48.6 \%)$ & $14(37.8 \%)$ & $3(8.1 \%)$ & $1(2.7 \%)$ & 0 & $19(51.3 \%)$ \\
\hline Skin SCC & $16(100 \%)$ & $10(62.5 \%)$ & $8(50.0 \%)$ & $1(6.2 \%)$ & 0 & $1(6.2 \%)$ & $6(37.5 \%)$ \\
\hline Pen $\mathrm{NT}^{\mathrm{a}}$ & $2(100 \%)$ & 0 & 0 & 0 & 0 & 0 & $2(100 \%)$ \\
\hline Skin $\mathrm{NT}^{\mathrm{a}}$ & $2(100 \%)$ & 0 & 0 & 0 & 0 & 0 & $2(100 \%)$ \\
\hline
\end{tabular}

No number, Pen penile, $N T$ non-tumor tissue, SCC squamous cell carcinoma

${ }^{\text {a Negative control }}$

\section{Discussion}

We here provide the first report of TERT-p mutation and its clinicopathologic significance in penile SCC. TERT$\mathrm{p}$ mutations were detected at a high frequency (48.6\%) in penile SCC, which, to our knowledge, are the most frequent mutations in penile SCC described to date (Ferrandiz-Pulido et al. 2015). Indeed, the majority of recurrent mutations reported in penile SCC are of low incidence (less than 10\%) (Ferrandiz-Pulido et al. 2015; Wang et al. 2019). Notably, out of 18 cases with TERT-p mutations, 14 were c. $-146 \mathrm{C}>\mathrm{T}$ and 3 were c.- $124 \mathrm{C}>\mathrm{T}$. These are known as mutation hotspots that have been reported to be the most common recurrent mutations in various organs and tend to be mutually exclusive, with two exceptions in which both mutations were identified in two cases of breast cancer (Huang et al. 2013). The remaining TERT-p mutation detected in our study was c.-124C $>$ A, which was found in both an excision and penectomy specimen of the same patient and was the only case of sarcomatoid carcinoma in our cohort. Histologically, the transitional area from conventional SCC to sarcomatoid carcinoma was included in this sarcomatoid carcinoma case. The c.$124 \mathrm{C}>$ A mutation was previously reported in one mammary phyllodes tumor, as well as in urothelial carcinoma, hepatocellular carcinoma, and glioma (Yoshida et al. 2015).

The mutation rate of TERT-p in cutaneous SCC, which was used as a positive control, is concordant with previous reports (Griewank et al 2013). Cheng et al. evaluated TERT-p mutations in SCCs from different anatomic sites, finding a mutation rate of $70 \%$ for both skin and urinary bladder SCCs, but only $20 \%$ for head and neck SCC, and no TERT-p mutations were identified in uterine cervix and lung cancer (Cheng et al. 2015). The authors suggested that this finding supports a hypothesis of different carcinogenesis mechanisms of SCCs from different anatomic sites. Penile SCC shows a similar frequency of TERT-p mutations to that reported for cutaneous SCC or urothelial cancer.
ETS transcription factors, whose binding sites are generated within the promoter region through TERT-p mutations, are upregulated by the mitogen-activated protein kinase (MAPK) pathway; therefore, TERT-p mutations may be associated with mutations in genes involved in the MAPK pathway (Horn et al. 2013). Indeed, tumors harboring TERTp mutation at high frequency, such as melanoma, thyroid papillary carcinoma, and glioma, are also well known for a high frequency of $B R A F$ mutation. Furthermore, significant coexistence of TERT-p and BRAF mutations, and their associations with adverse clinicopathological factors have been reported in some tumors, including papillary thyroid carcinoma and melanoma, suggesting that these coexisting mutations reflect a unique mechanism to upregulate the expression of TERT, cooperatively contributing to the aggressiveness of these tumors (Macerola et al. 2015; Xing et al. 2014). Likewise, we speculated that other mutations might coexist and act cooperatively with TERT-p mutations in penile SCC.

There have been only a few studies conducted on genetic alterations in penile SCC, including data obtained through whole-exome sequencing (Ferrandiz-Pulido et al. 2015; Wang et al. 2019). In general, the detection rates are low in all cases (detection rates of 3-9\%), the main mutated genes identified in penile SCC include KRAS, HRAS, NRAS, and PIK3CA, which are involved in the MAPK pathway (Ferrandiz-Pulido et al. 2015; Silva Amancio et al. 2017; Spiess et al. 2016; Wang et al. 2019). However, the mutational status of TERT-p was not investigated in that cohort (FerrandizPulido et al. 2015). Therefore, further studies on mutations coexisting with TERT-p and their significance are needed to obtain a deeper understanding of the roles of TERT-p mutations in penile carcinogenesis.

Penile SCCs are pathologically divided into two groups, HPV-related and non-HPV-related. The key oncogenic mechanism of HPV in humans is its ability to reactivate telomerase, which largely involves the E6 protein of HR-HPV. E6 protein directly binds to hTERT and telomeric DNA or participates in the epigenetic and post-transcriptional 
Table 3 Associations between $T E R T$ promoter mutation and clinicopathologic parameters in 34 patients with invasive penile squamous cell carcinoma

\begin{tabular}{|c|c|c|c|}
\hline Parameters & $T E R T$-p wild $(N=19)$ & $T E R T$-p mutant $(N=15)$ & $p$ value \\
\hline Histologic subtype & & & $0.005 *$ \\
\hline HPV-related & $12(63.2 \%)$ & $2(13.3 \%)$ & \\
\hline Non-HPV-related & $7(36.8 \%)$ & $13(86.7 \%)$ & \\
\hline Histologic grade & & & $0.036^{*}$ \\
\hline WD & $3(15.8 \%)$ & $7(46.7 \%)$ & \\
\hline MD & $5(26.3 \%)$ & $4(26.7 \%)$ & \\
\hline PD & $11(57.9 \%)$ & $4(26.7 \%)$ & \\
\hline Acantholysis & & & 0.462 \\
\hline Absent & $15(78.9 \%)$ & $10(66.7 \%)$ & \\
\hline Present & $4(21.1 \%)$ & $5(33.3 \%)$ & \\
\hline Lymphovascular invasion & & & 0.409 \\
\hline Absent & $10(52.6 \%)$ & $10(66.7 \%)$ & \\
\hline Present & $9(47.4 \%)$ & $5(33.3 \%)$ & \\
\hline Perineural invasion & & & 0.697 \\
\hline Absent & $13(68.4 \%)$ & $12(80.0 \%)$ & \\
\hline Present & $6(31.6 \%)$ & $3(20.0 \%)$ & \\
\hline Koilocytosis & & & 0.260 \\
\hline Absent & $10(52.6 \%)$ & $5(33.3 \%)$ & \\
\hline Present & $9(47.4 \%)$ & $10(66.7 \%)$ & \\
\hline \multicolumn{4}{|l|}{ Mitosis (/HPF) } \\
\hline Mean \pm SD & $9.02 \pm 6.92$ & $2.68 \pm 1.71$ & \\
\hline$\leq 8$ & $10(52.6 \%)$ & $15(100 \%)$ & $0.001^{*}$ \\
\hline$>8$ & $9(47.4 \%)$ & $0(0 \%)$ & $0.002 *$ \\
\hline Tumor thickness $(\mathrm{cm})$ & & & 0.300 \\
\hline$<1.2$ & $11(57.9 \%)$ & $6(40.0 \%)$ & \\
\hline$\geq 1.2$ & $8(42.1 \%)$ & $9(60.0 \%)$ & \\
\hline Necrosis & & & $0.045^{*}$ \\
\hline Absent & $7(36.8 \%)$ & $11(73.3 \%)$ & \\
\hline Present & $12(63.2 \%)$ & $4(26.7 \%)$ & \\
\hline Tumor infiltrating lymphocytes & & & 0.476 \\
\hline Absent to non-brisk & $11(57.9 \%)$ & $11(73.3 \%)$ & \\
\hline Brisk & $8(42.1 \%)$ & $4(26.7 \%)$ & \\
\hline Ulceration & & & 0.300 \\
\hline Absent & $8(42.1 \%)$ & $9(60.0 \%)$ & \\
\hline Present & $11(57.9 \%)$ & $6(40.0 \%)$ & \\
\hline Peripheral budding & & & 0.968 \\
\hline Absent to focal $(\leq 10 \%)$ & $10(52.6 \%)$ & $8(47.4 \%)$ & \\
\hline Diffuse $(>10 \%)$ & $9(53.3 \%)$ & $7(46.7 \%)$ & \\
\hline Intraepithelial microabscess & & & 0.152 \\
\hline Absent & $9(47.4 \%)$ & $3(20.0 \%)$ & \\
\hline Present & $10(52.6 \%)$ & $12(80.0 \%)$ & \\
\hline T stage & & & 0.679 \\
\hline 1 & $7(36.8 \%)$ & $3(20.0 \%)$ & \\
\hline 2 & $7(36.8 \%)$ & $9(60.0 \%)$ & \\
\hline 3 & $5(26.3 \%)$ & $3(20.0 \%)$ & \\
\hline AJCC stage & & & 0.128 \\
\hline I, II & $11(57.9 \%)$ & $13(86.7 \%)$ & \\
\hline III, IV & $8(42.1 \%)$ & $2(13.3 \%)$ & \\
\hline $\mathrm{LN}$ or distant metastases & & & $0.020^{*}$ \\
\hline Absent & $10(52.6 \%)$ & $14(93.3 \%)$ & \\
\hline Present & $9(47.4 \%)$ & $1(6.7 \%)$ & \\
\hline
\end{tabular}


Table 3 (continued)

\begin{tabular}{llll}
\hline Parameters & TERT-p wild $(N=19)$ & TERT-p mutant $(N=15)$ & $p$ value \\
\hline $\begin{array}{l}\text { Tumor size }(\mathrm{cm}) \\
\quad \leq 3\end{array}$ & $12(63.2 \%)$ & $4(26.7 \%)$ & $0.045^{*}$ \\
$\quad>3$ & $7(36.8 \%)$ & $11(73.3 \%)$ & \\
Age, years & & & 0.560 \\
$\quad$ Mean \pm SD & $67.47 \pm 13.24$ & $64.27 \pm 13.04$ & $0.005^{*}$ \\
PeIN & & & \\
Non-HPV-related type & $7(36.8 \%)$ & $2(13.3 \%)$ & \\
HPV-related type & $12(63.2 \%)$ & & \\
\hline
\end{tabular}

$H P V$ human papilloma virus, $H P F$ high-power field, $W D$ well differentiated, $M D$ moderately differentiated, $P D$ poorly differentiated, $A J C C$ the American Joint Committee on Cancer, $L N$ lymph node, PeIN penile intraepithelial neoplasia

$* p<0.05$

Fig. 1 Immunohistochemical staining for $\mathrm{p} 16^{\mathrm{INK} 4 \mathrm{a}}$ and MIB-1 in penile SCC. a Diffuse strong positivity for $\mathrm{p} 16^{\mathrm{INK} 4 \mathrm{a}}$ in $T E R T$-p wild-type penile SCC. b $16^{\text {INK4a }}$ negativity in TERTp-mutated penile SCC. $\mathbf{c}$ High MIB-1 labeling index. d Low MIB-1 labeling index

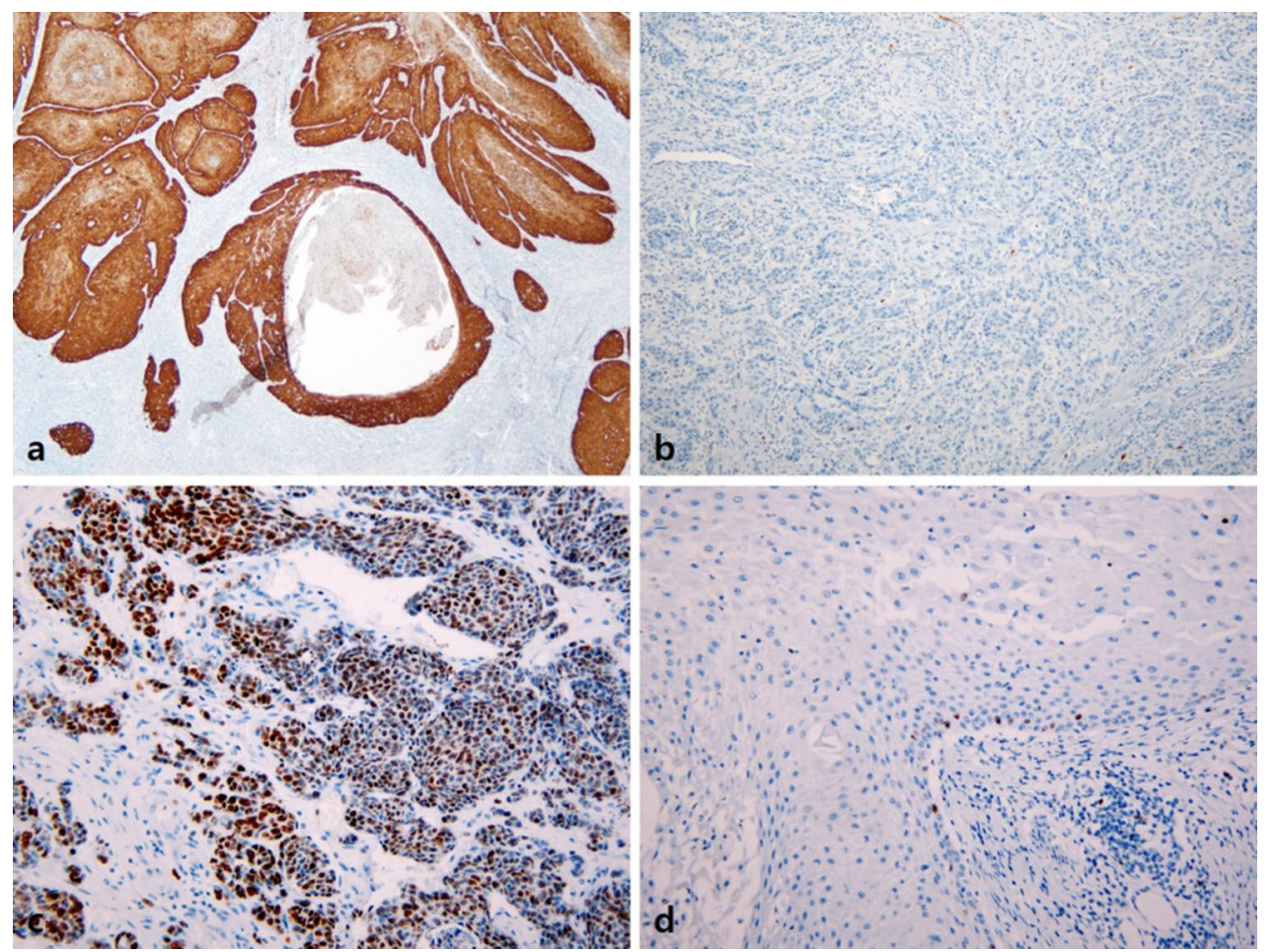

regulation of hTERT (Katzenellenbogen 2017a, b). In contrast, E7 protein can maintain telomere length by the alternative lengthening of the telomerase pathway, irrespective of hTERT. A particularly interesting finding of this study was the much higher frequency of TERT-p mutation in non-HPVrelated type of penile SCC, based on both histologic classification and $\mathrm{p} 16^{\mathrm{INK} 4 \mathrm{a}}$ immunoreactivity. Although we did not investigate the presence of HPV DNA, p16 ${ }^{\mathrm{INK} 4 \mathrm{a}}$ immunostaining has been established and widely used as a surrogate marker for transcriptionally active HR-HPV (Aumayr et al. 2013; Cubilla et al. 2011). TERT-p mutation was found in only 1 of 12 cases with $\mathrm{p} 16^{\text {INK4a }}$ positivity. In contrast, 14 of the $22(63.6 \%)$ cases showing negative immunoreactivity to $\mathrm{p} 16^{\mathrm{INK} 4 \mathrm{a}}$ harbored a TERT-p mutation. Similarly, the presence of differentiated PeIN, which is known to be a nonHPV-related type of PeIN in the adjacent mucosa, also correlated with TERT-p mutation in this study. These results suggest two major pathogenetic pathways of penile SCC that differ not only with respect to the relation to HPV but also with respect to the underlying molecular mechanism, with different mechanisms of telomerase activation. We speculate that in HPV-related penile SCC, telomerase is activated by HPV E6 in the absence of TERT-p mutation, whereas mutations of TERT-p might play a role in the mechanism of telomerase activation in non-HPV-related penile cancer. 


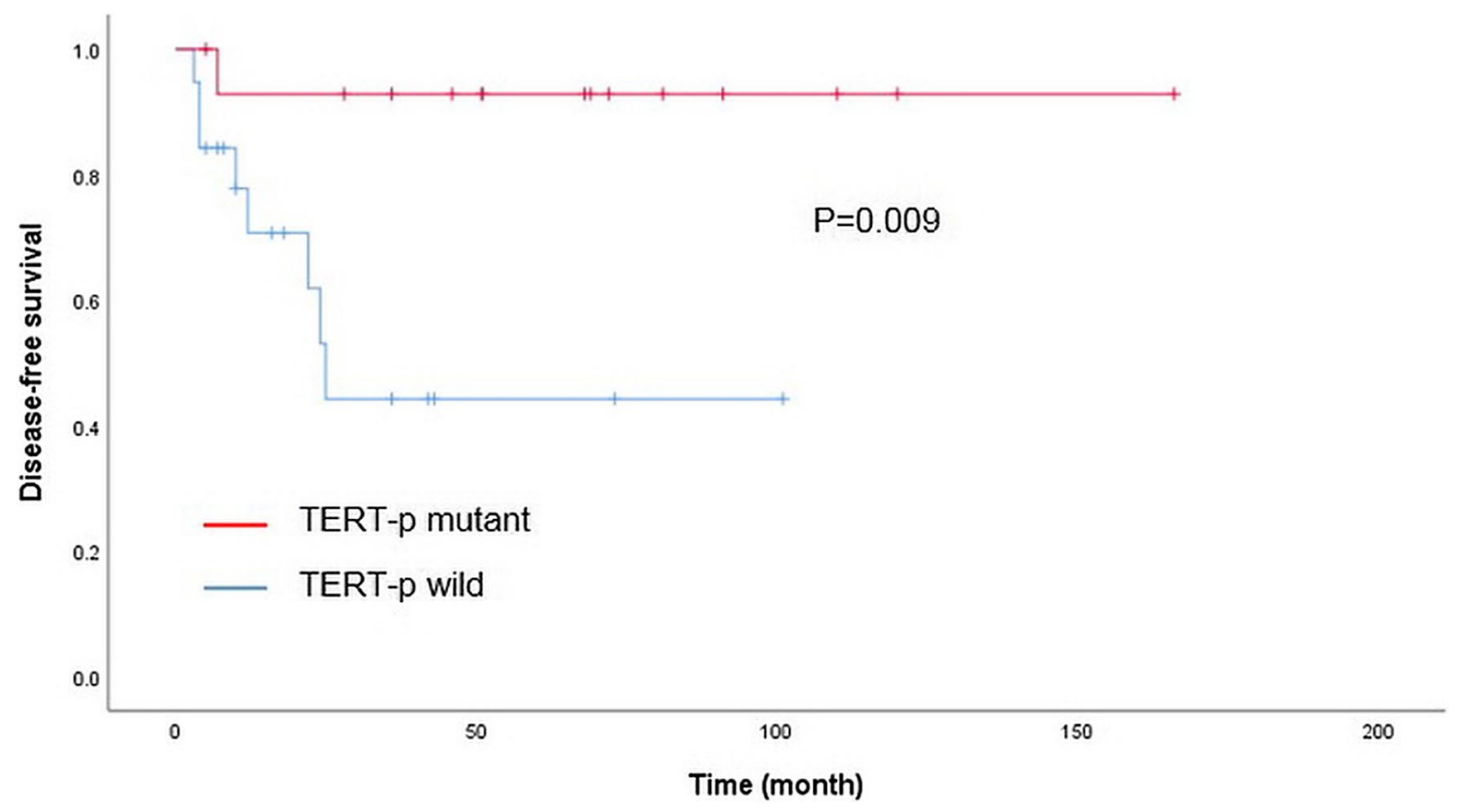

Fig. 2 Kaplan-Meier analysis of the impact of TERT-p mutation on disease-free survival of patients with penile SCC

Table 4 Disease-free survival univariate and multivariate Cox regression analyses in 34 patients with penile squamous cell carcinoma

\begin{tabular}{|c|c|c|c|c|}
\hline \multirow[t]{3}{*}{ Variable } & \multicolumn{4}{|l|}{ Disease-free survival } \\
\hline & \multicolumn{2}{|l|}{ Univariate } & \multicolumn{2}{|l|}{ Multivariate } \\
\hline & $\mathrm{HR}(95 \% \mathrm{CI})$ & $p$ value & HR (95\% CI) & $p$ value \\
\hline Histologic grade (WD vs M to PD) & $3.01(0.37-24.20)$ & 0.301 & & \\
\hline Stage (I, II vs III, IV) & $29.37(3.58-240.87)$ & $0.002 *$ & $179.50(5.37-5997.0)$ & $0.004 *$ \\
\hline Subtype (HPV vs non-HPV-related) & $0.50(0.13-1.89)$ & 0.311 & & \\
\hline LV invasion & $6.02(1.24-29.25)$ & $0.026^{*}$ & $0.05(0.0-0.94)$ & $0.046^{*}$ \\
\hline Perineural invasion & $4.39(1.17-16.46)$ & $0.028^{*}$ & $3.65(0.66-20.13)$ & 0.137 \\
\hline Necrosis & $4.67(1.17-16.46)$ & $0.031 *$ & $2.33(0.46-11.77)$ & 0.308 \\
\hline Mitotic figure $(\leq 8$ vs $>8$ (/HPF)) & $2.80(0.74-10.55)$ & 0.128 & & \\
\hline MIB-1 LI ( $\leq 40$ vs > 40) & $1.99(0.53-7.50)$ & 0.308 & & \\
\hline $\mathrm{p} 16^{\mathrm{INK} 4 \mathrm{a}}$ positivity & $2.70(0.71-10.28)$ & 0.147 & & \\
\hline$T E R T-\mathrm{p}$ (wild vs mutant) & $0.10(0.01-0.82)$ & $0.032 *$ & $0.37(0.03-4.10)$ & 0.417 \\
\hline
\end{tabular}

$H R$ hazard ratio, $C I$ confidence interval, $W D$ well differentiated, $M$ to $P D$ moderately to poorly differentiated, $H P F$ high-power field, $L V$ lymphovascular, $L I$ labeling index, $H P V$ human papilloma virus

$*_{p}<0.05$
Based on this assumption, TERT-p mutation is suggested as a new potential therapeutic target in non-HPV-related cancer. Although penile cancer is typically divided into two distinct groups according to clinicopathologic features and its relation with HPV, there is no difference in the treatment of these different types, which is mainly due to the low prevalence and limited data to understand the detailed mechanisms for targeted therapy. In addition, HPV-related cancer is known to respond better to radiation or chemoradiation therapy and shows a more favorable clinical course than non-HPV-related cancer (Eich et al. 2020). Therefore, further studies are needed to validate our assumption and develop targeted therapies for penile carcinoma, especially for the non-HPV-related type.

As mentioned above, several previous studies have shown associations between TERT-p mutations and adverse clinicopathologic parameters or poor prognosis in various types of human cancers, including thyroid papillary carcinoma, melanoma, bladder cancer, and glioma (Chen et al. 2014a; Griewank et al. 2014; Lee et al. 2015; Nasirden et al. 2016; Simon et al. 2015; Wang et al. 2014), which was the main motivation for the present study. 
However, in contrast to these previous reports, we found a correlation between TERT-p mutation with favorable clinicopathologic parameters in penile SCC, including a low histologic grade, low mitotic count, absence of necrosis, and low MIB-1 index. These results are in line with the fact that TERT-p mutations were more frequently detected in non-HPV-related tumors, which are generally low-grade tumors with low mitotic activities (Steinestel et al. 2015). Similarly, the tumors in non-HPV-related penile SCC tend to be larger than those in the HPV-related type, which may explain the correlation between TERT-p mutant type and larger tumor size. Notably, lymph node or distant metastasis rarely occurred in patients with TERT-p mutant type of penile SCC; however, further studies in a larger cohort will be needed to validate this result. In addition, these patients had a significantly longer DFS than patients without TERT-p mutation based on Kaplan-Meier and log-rank analysis. In the univariate Cox proportional hazard model, the presence of $T E R T$-p mutation was a significant factor for predicting longer DFS, but this significant effect was not maintained in the multivariate analysis. Instead, clinical stage and lymphovascular permeation were identified as independent predictors for DFS. TERT-p mutant type, although not significant, accounted for lower stage tumors in a large proportion of our cohort and hence could be one of the confounding factors for the determination of DFS.

Given the very low incidence of penile carcinoma, this study represents a relatively thorough analysis; nevertheless, the limitation of this study is its relatively small sample size, which can be a source of potential bias. Therefore, further investigations in larger cohorts of patients and in vitro studies are needed to validate our results. Our study shows that TERT-p mutations are far more frequent in non-HPV-related penile SCC based on both histological classification and $\mathrm{p} 16^{\mathrm{INK} 4 \mathrm{a}}$ immunopositivity, and offer insight into the pathogenetic mechanisms of this rare disease.

Supplementary Information The online version contains supplementary material available at https://doi.org/10.1007/s00432-021-03514-9.

Acknowledgements We would like to thank Dr. Yoon Jin Cha for providing sample material, and Ji Young Yoon, Se Hwa Son, and Moon Chang Kim for their technical support. This work was supported by the new faculty research fund of Ajou University School of Medicine.

Author contributions SK wrote the manuscript. JEK and NHC performed the histologic examination. JHH and JK analyzed the immunohistochemical results. SJK, SHC, and SIK collected the clinical data. JSK and BP performed the statistical analyses. JEK designed the study and supervised the experiments. All the authors read and approved the final manuscript.

Funding This work was supported by the new faculty research fund of Ajou University School of Medicine.
Availability of data and materials The datasets used and/or analyzed during the current study are available from the corresponding author on reasonable request.

\section{Compliance with ethical standards}

Conflict of interest The authors declare that they have no competing interests.

Ethical approval This study was approved by the Institutional Review Board of Ajou University School of Medicine and Yonsei University Health System.

Open Access This article is licensed under a Creative Commons Attribution 4.0 International License, which permits use, sharing, adaptation, distribution and reproduction in any medium or format, as long as you give appropriate credit to the original author(s) and the source, provide a link to the Creative Commons licence, and indicate if changes were made. The images or other third party material in this article are included in the article's Creative Commons licence, unless indicated otherwise in a credit line to the material. If material is not included in the article's Creative Commons licence and your intended use is not permitted by statutory regulation or exceeds the permitted use, you will need to obtain permission directly from the copyright holder. To view a copy of this licence, visit http://creativecommons.org/licenses/by/4.0/.

\section{References}

Allory Y, Beukers W, Sagrera A et al (2014) Telomerase reverse transcriptase promoter mutations in bladder cancer: high frequency across stages, detection in urine, and lack of association with outcome. Eur Urol 65:360-366. https://doi.org/10.1016/j.eurur o.2013.08.052

Arita H, Narita Y, Fukushima S et al (2013) Upregulating mutations in the TERT promoter commonly occur in adult malignant gliomas and are strongly associated with total $1 \mathrm{p} 19 \mathrm{q}$ loss. Acta Neuropathol 126:267-276. https://doi.org/10.1007/s00401-013-1141-6

Aumayr K, Susani M, Horvat R et al (2013) P16INK4A immunohistochemistry for detection of human papilloma virus-associated penile squamous cell carcinoma is superior to in-situ hybridization. Int J Immunopathol Pharmacol 26:611-620. https://doi. org/10.1177/039463201302600305

Baudino TA (2015) Targeted cancer therapy: the next generation of cancer treatment. Curr Drug Discov Technol 12:3-20. https://doi. org/10.2174/1570163812666150602144310

Chen C, Han S, Meng L, Li Z, Zhang X, Wu A (2014a) TERT promoter mutations lead to high transcriptional activity under hypoxia and temozolomide treatment and predict poor prognosis in gliomas. PLoS ONE 9:e100297. https://doi.org/10.1371/journ al.pone.0100297

Chen YL, Jeng YM, Chang CN et al (2014b) TERT promoter mutation in resectable hepatocellular carcinomas: a strong association with hepatitis $\mathrm{C}$ infection and absence of hepatitis B infection. Int J Surg 12:659-665. https://doi.org/10.1016/j.ijsu.2014.05.066

Cheng KA, Kurtis B, Babayeva S et al (2015) Heterogeneity of TERT promoter mutations status in squamous cell carcinomas of different anatomical sites. Ann Diagn Pathol 19:146-148. https://doi. org/10.1016/j.anndiagpath.2015.03.005

Cubilla AL, Lloveras B, Alejo M, Clavero O, Chaux A, Kasamatsu E et al (2011) Value of p16(INK)(4)(a) in the pathology of invasive penile squamous cell carcinomas: a report of 202 cases. Am 
J Surg Pathol 35:253-261. https://doi.org/10.1097/PAS.0b013 e318203cdba

Cubilla AL, Amin MB, Ayala A et al (2016) Tumors of the penis. In: Moch H, Humphrey PA, Ulbright TM, Reuter VE (eds) Who classification of tumors of the urinary system and male genital organs, 4th edn. IARC Press, Lyon, pp 260-279

Eich ML, Pena MDCR, Schwartz L, Granada CP, Rais-Bahrami S, Giannico G et al (2020) Morphology, p16, HPV, and outcomes in squamous cell carcinoma of the penis: a multi-institutional study. Hum Pathol 96:79-86. https://doi.org/10.1016/j.humpa th.2019.09.013

Ferrandiz-Pulido C, Hernandez-Losa J, Masferrer E, Vivancos A, Somoza R, Mares R et al (2015) Identification of somatic gene mutations in penile squamous cell carcinoma. Genes Chromosomes Cancer 54:629-637. https://doi.org/10.1002/gcc.22274

Griewank KG, Murali R, Schilling B et al (2013) TERT promoter mutations are frequent in cutaneous basal cell carcinoma and squamous cell carcinoma. PLoS ONE 8:e80354. https://doi. org/10.1371/journal.pone.0080354

Griewank KG, Murali R, Puig-Butille JA, Schilling B, Livingstone E, Potrony $M$ et al (2014) TERT promoter mutation status as an independent prognostic factor in cutaneous melanoma. J Natl Cancer Inst 106:246. https://doi.org/10.1093/jnci/dju246

Gunes C, Rudolph KL (2013) The role of telomeres in stem cells and cancer. Cell 152:390-393. https://doi.org/10.1016/j. cell.2013.01.010

Horn S, Figl A, Rachakonda PS (2013) TERT promoter mutations in familial and sporadic melanoma. Science 339:959-961. https:// doi.org/10.1126/science. 1230062

Huang FW, Hodis E, Xu MJ et al (2013) Highly recurrent TERT promoter mutations in human melanoma. Science 339:957-959. https://doi.org/10.1126/science.1229259

Katzenellenbogen RA (2017a) Activation of telomerase by HPVs. Virus Res 231:50-55. https://doi.org/10.1016/j.virus res.2016.11.003

Katzenellenbogen R (2017b) Telomerase induction in HPV infection and oncogenesis. Viruses 9:180. https://doi.org/10.3390/ v9070180

Kim JW, Kim YS, Ko WJ et al (2018) Prognostic factors of penile cancer and the efficacy of adjuvant treatment after penectomy: results from a multi-institution study. J Korean Med Sci 33:e233. https://doi.org/10.3346/jkms.2018.33.e233

Kinde I, Munari E, Faraj SF, Hruban RH, Schoenberg M, Bivalacqua $\mathrm{T}$ et al (2013) TERT promoter mutations occur early in urothelial neoplasia and are biomarkers of early disease and disease recurrence in urine. Cancer Res 73:7162-7167. https:// doi.org/10.1158/0008-5472.CAN-13-2498

Kyo S, Takakura M, Fujiwara T (2008) Understanding and exploiting hTERT promoter regulation for diagnosis and treatment of human cancers. Cancer Sci 99:1528-1538. https://doi.org/10.1 111/j.1349-7006.2008.00878.x

Lee S, Barnhill RL, Dummer R, Dalton J, Wu J, Pappo A et al (2015) TERT promoter mutations are predictive of aggressive clinical behavior in patients with spitzoid melanocytic neoplasms. Sci Rep 5:11200. https://doi.org/10.1038/srep11200

Liu X, Bishop J, Shan Y et al (2013a) Highly prevalent TERT promoter mutations in aggressive thyroid cancers. Endocr Relat Cancer 20:603-610

Liu X, Wu G, Shan Y et al (2013b) Highly prevalent TERT promoter mutations in bladder cancer and glioblastoma. Cell Cycle 12:1637-1638. https://doi.org/10.1530/ERC-13-0210

Macerola E, Loggini B, Giannini R, Garavello G, Giordano M, Proietti A et al (2015) Coexistence of TERT promoter and BRAF mutations in cutaneous melanoma is associated with more clinicopathological features of aggressiveness. Virchows Arch 467:177-184. https://doi.org/10.1007/s00428-015-1784-x
Mannweiler S, Sygulla S, Winter E et al (2013) Two major pathways of penile carcinogenesis: HPV-induced penile cancers overexpress $\mathrm{p} 16^{\text {ink4a }}$, HPV-negative cancers associated with dermatoses express p53, but lack p16 $6^{\text {ink4a }}$ overexpression. J Am Acad Dermatol 69:73-81. https://doi.org/10.1016/j.jaad.2012.12.973

Melo M, da Rocha AG, Vinagre J, Batista R, Peixoto J, Tavares $\mathrm{C}$ et al (2014) TERT promoter mutations are a major indicator of poor outcome in differentiated thyroid carcinomas. J Clin Endocrinol Metab 99:E754-765. https://doi.org/10.1210/ jc.2013-3734

Nasirden A, Saito T, Fukumura Y, Hara K, Akaike K, KurisakiArakawa A et al (2016) In Japanese patients with papillary thyroid carcinoma, TERT promoter mutation is associated with poor prognosis, in contrast to BRAF (V600E) mutation. Virchows Arch 469:687-696. https://doi.org/10.1007/s0042 8-016-2027-5

Populo H, Boaventura P, Vinagre J et al (2014) TERT promoter mutations in skin cancer: the effects of sun exposure and X-irradiation. J Invest Dermatol 134:2251-2257. https://doi. org/10.1038/jid.2014.163

Qu Y, Dang S, Wu K, Shao Y, Yang Q, Ji M et al (2014) TERT promoter mutations predict worse survival in laryngeal cancer patients. Int J Cancer 135:1008-1010. https://doi.org/10.1002/ ijc. 28728

Rubin MA, Kleter B, Zhou M et al (2001) Detection and typing of human papillomavirus DNA in penile carcinoma: evidence for multiple independent pathways of penile carcinogenesis. Am J Pathol 159:1211-1218. https://doi.org/10.1016/S0002 -9440(10)62506-0

Scott GA, Laughlin TS, Rothberg PG (2014) Mutations of the TERT promoter are common in basal cell carcinoma and squamous cell carcinoma. Mod Pathol 27:516-523. https://doi.org/10.1038/ modpathol.2013.167

Shimizu S, Miyazaki A, Sonoda T, Koike K, Ogi K, Kobayashi JI et al (2018) Tumor budding is an independent prognostic marker in early stage oral squamous cell carcinoma: With special reference to the mode of invasion and worst pattern of invasion. PLoS ONE 13:e0195451. https://doi.org/10.1371/journ al.pone. 0195451

Silva Amancio AM, Cunha IW, Neves JI, Quetz JD, Carraro DM, Rocha RM et al (2017) Epidermal growth factor receptor as an adverse survival predictor in squamous cell carcinoma of the penis. Hum Pathol 61:97-104. https://doi.org/10.1016/j.humpa th.2016.07.041

Simon M, Hosen I, Gousias K, Rachakonda S, Heidenreich B, Gessi $M$ et al (2015) TERT promoter mutations: a novel independent prognostic factor in primary glioblastomas. Neuro Oncol 17:45-52. https://doi.org/10.1093/neuonc/nou 158

Spiess PE, Dhillon J, Baumgarten AS et al (2016) Pathophysiological basis of human papillomavirus in penile cancer: Key to prevention and delivery of more effective therapies. CA Cancer J Clin 66:481-495. https://doi.org/10.3322/caac.21354

Steinestel J, Al Ghazal A, Arndt A, Schnoeller TJ, Schrader AJ, Moeller P et al (2015) The role of histologic subtype, p16(INK4a) expression, and presence of human papillomavirus DNA in penile squamous cell carcinoma. BMC Cancer 15:220. https:// doi.org/10.1186/s12885-015-1268-z

Suarez-Bonnet A, Willis C, Pittaway R et al (2018) Molecular carcinogenesis in equine penile cancer: a potential animal model for human penile cancer. Urol Oncol 36:532.e9-532.e18. https ://doi.org/10.1016/j.urolonc.2018.09.004

van Nistelrooij AM, Zwarthoff EC, Post E et al (2014) Absence of TERT promoter mutations in esophageal adenocarcinoma. Int $\mathrm{J}$ Cancer 134:2014-2015. https://doi.org/10.1002/ijc.28527

Vinagre J, Pinto V, Celestino R et al (2014) Telomerase promoter mutations in cancer: an emerging molecular biomarker? 
Virchows Arch 465:119-133. https://doi.org/10.1007/s0042 8-014-1608-4

Wang K, Liu T, Ge N, Liu L, Yuan X, Liu J et al (2014) TERT promoter mutations are associated with distant metastases in upper tract urothelial carcinomas and serve as urinary biomarkers detected by a sensitive castPCR. Oncotarget 5:12428-12439. https://doi.org/10.18632/oncotarget.2660

Wang Y, Wang K, Chen Y, Zhou J, Liang Y, Yang X et al (2019) Mutational landscape of penile squamous cell carcinoma in a Chinese population. Int J Cancer 145:1280-1289. https://doi. org/10.1002/ijc.32373

Xing M, Liu R, Liu X, Murugan AK, Zhu G, Zeiger MA et al (2014) BRAF V600E and TERT promoter mutations cooperatively identify the most aggressive papillary thyroid cancer with highest recurrence. J Clin Oncol 32:2718-2726. https://doi. org/10.1200/JCO.2014.55.5094

Yoshida M, Ogawa R, Yoshida H, Maeshima A, Kanai Y, Kinoshita $\mathrm{T}$ et al (2015) TERT promoter mutations are frequent and show association with MED12 mutations in phyllodes tumors of the breast. Br J Cancer 113:1244-1248. https://doi.org/10.1038/ bjc. 2015.326

Publisher's Note Springer Nature remains neutral with regard to jurisdictional claims in published maps and institutional affiliations. 